\title{
Formulation and Evaluation of Clay Face Pack
}

\author{
Swati Siddheshwar Londhe ${ }^{1, *}$, Amol Arun Joshi ${ }^{1}$, Geeta Narsingrao Sapkale ${ }^{1}$, Mangesh Gautam Bhosale ${ }^{2}$ \\ ${ }^{1}$ K. T. Patil College of Pharmacy, Siddharth Nagar, Barshi Road, Osmanabad, Maharashtra, INDIA. \\ 2Ramkrishna Paramhans Mahavidyalay, Osmanabad, Maharashtra, INDIA.
}

\begin{abstract}
Background: The skin is a very sensitive protective layer for the human body and is exposed to environmental pollution, so it is very important to protect the skin. Facial skin can be protected by using various cosmetics designed for facial applications. It can be a face cream, lotion mask or clay mask, etc. These gels have also been used in various dermatological preparations, such as benzoyl peroxide acne masks. They can also play an important role in the treatment of eczema, abscesses, sores and sores. Its main role is to stimulate the metabolism thanks to its blocking effect Amba haldi is added as an active ingredient of this formula. Methods: It was prepared by using extraction method. The most important property of Manjishta is to provide more equitable complexity. As the clay mask is dried over the face, it firm and reduces mechanical convergence. The presence of absorbent clay, such as bentonite and kaoline, is particularly excellent in oily compassion and immediately generates a significant cleaning effect. Results: The clay masks were evaluated using various test methods. This Clay mask get rid of all skin problems like it uncloge the
\end{abstract}

pores and removes pimples as well as acne marks. Arjuna used in the pack which gives improvement on acne scars. It reveals skin clear and brighter. Conclusion: The formulation after being tested on healthy female volunteers, the solution produced amazing results. To study scientifically verified that herbal clay face pack having enough potential to give efficient glowing effect on skin.

Key words: Bentonite, Clear, Cosmetics, Kaolin, Natural, Standardization etc.

\section{Correspondence}

Mrs. Swati Siddheshwar Londhe

K. T. Patil College of Pharmacy, Siddharth Nagar, Barshi Road,

Osmanabad-413501, Maharashtra, INDIA.

Email id: swatibhosale4444@gmail.com

DOI: 10.5530/ijpi.2021.4.78

\section{INTRODUCTION}

Clay masks are by far a longtime favorite. Chinese clay, colloidal kaolin, whole earth, or smectite clay (i.e. bentonite, magnesium aluminum silicate, and hectorite) may be used as "clay material". Natural mectite clay, commonly known as bentonite and kaolin clay, is often the main ingredient in clay masks. Bentonite gel has been described as soothing to the skin. Most clay are off-white, but white, red, yellow, brown, blue, green, purple, and even black clays are known. Zinc oxide can be added. On the other hand, the addition of dark clay and dyes could allow the marketing of black or green sea mud masks. Other mask ingredients may include surfactants, emulsifiers, and emollients. ${ }^{1}$ Gums and polymers such as xanthan, guar, methylcellulose or carrageen a may be added to stabilize the suspension of the solid and contribute to the mechanical strength of the dry film. Glycerin, propylene glycol, butylene glycol or sorbitol may be added as a plasticizer to improve spread and skin feel and as a humectant to control the rate of drying. They will also improve product long-term stability, reducing cracking and delamination at cold temperatures or during the freeze/thaw cycle. Adding active ingredients such as sulfur, astringents, bleach, benzoyl peroxide or other active ingredients can give the mask special properties. The regulated active ingredients must be stable and recoverable in the mask throughout the shelf life of the product. Due to their consistency and consistency, clay masks are often packaged in single-use jars, ampoules or sachets. Viscosity can be controlled by the formulation, but a mask with a heavier consistency is generally preferred. The addition of raw materials such as conditioners, surfactants or antibacterial agents can disrupt the colloidal structure created by bentonite. Use should be kept below 3\%, as higher cation concentrations can precipitate anionic bentonite and cause instability. Cationic raw materials should be incorporated at the end of the mixing process, not at the start. Adding a cationic agent before hydration of the bentonite will cause poor hydration which will reduce or even eliminate its desirable properties. The cations can also react with other anionic constituents, producing flocculation and less stable products. The correct balance of cations can create interesting masking or exfoliating properties and residual skin conditioning effects. Other ingredients commonly added to masks and scrubs are polyethylene balls, lufa and oatmeal. They help carry out the marketing story, help remove masks, and change perceptions about skin cleansing. Many clay masks also include an emulsion system. Appropriate equipment is required to work with these types of products. ${ }^{2}$ The resulting viscosity and thermal requirements can limit a laboratory's ability to work. Scaling up the batch size may reveal rheological differences in formulation. Mixtures marketed by commodities will not improve the appearance of skin by cleansing, beautifying and increasing skin tone attraction. Since ancient times completely different herbs have been used to improve, beautify, and manage them. The facial skin is the main part of the body, indicating the health of the individual. ${ }^{1,2}$ It is made up of substances such as amino acids, fats and carbohydrates, and so on. To provide the balanced nutrition the skin needs. Shiny and healthy. ${ }^{3}$ In Ayurveda, the aromatic mixture named "mukhalepa" is used as a medical aid for the face. This spice blend is applied to the face to treat inflammation, pimples, boils (Ghadde), spots and pigmentation, melasma on the face. The skin of the face is the main part of the body, which can be a mirror of the health of the private space. A balanced diet containing the amino acids, fats and carbohydrate surface units necessary to keep the skin clear, shiny and healthy. Historically, women were very beauty conscious and took special care of their specific skin types. Even today people, especially in rural and hilly areas, choose natural remedies like herbal extracts for various cosmetic functions like neem, aloe, tulsi, orange peel, rose, etc. ${ }^{3}$ 


\section{MATERIALS AND METHODS}

\section{Materials}

All the natural materials utilized in this study that is, Arjuna powder, Amba haldi, Aloe vera, Rose Petal Powder, Manjishta were purchased from native market Osmanabad in an exceedingly variety of dried powder and were genuine at Pharmacognosy department of K.T Patil college of Pharmacy, Osmanabad.

The details of the stuff used for the formulation (Table 1) of corrective are mentioned below;

- Arjuna - Terminalia Arjuna Bark strengthens the skin barrier and induces secretion production to scale back the signs of dry skin and defend the skin from external challenges. It reduces disease of skin marks (Ghadde) on face. ${ }^{4}$

- Amba haldi is having very good healing property - It is used for Fairness and Treat acne and Boils, Also remove Scars, marks and keeps away Wrinkles - Amba haldi is antibacterial, antifungal and antioxidant. It helps in treating skin problems. ${ }^{5}$

- Aloe vera- It contains enzymes, Vitamins A and C, Extreme antiageing, antioxidant properties and it's extremely medication. It will facilitate treat burns, disease of the skin; it provides lots of moisture to dry skin. ${ }^{6}$

- $\quad$ Rose floral leaf powder is made in ascorbic acid and different antioxidants, that facilitate to spice up the scleroprotein production and strengthens skin cells and tissues. Impact of applying rose floral leaf powder therefore fast that, it entirely removes blemishes and disease of skin scars from skin. ${ }^{6}$

\section{METHOD OF FORMULATION}

\section{Preparation of Extract}

- The collected Arjuna barks were cut into small pieces then all powders i.e Amba haldi, Rose petal powder, Manjishta powder are then added into distilled water (quantity sufficient) then boiled it for $15 \mathrm{~min}$ and cooled for $5 \mathrm{~min}$. and then filtered that extract with muslin cloth. ${ }^{3}$

- The bentonite needs to be hydrated in the water prior to addition of the other ingredients. So bentonite is added. ${ }^{7}$

- The thickener (Methyl Cellulose) is added into the water vortex either slurried with a propylene glycol as a humectants or sifted in slowly to avoid the formation of aggregates.

- Mix until uniform, and then added Aloe vera gel and the kaolin as oil absorbent. Followed with the humectants and added the sodium lauryl sulfate as a surfactant and methyl paraben as preservative. ${ }^{8}$ The prepared formulated face packs shown in Figure 1.

\section{Evaluation Tests}

- Color: The Mask is Brown in color.

- Consistency: It is smooth and light to spread.

- Odour: It is odourless which last long even after washing the face with water.

- $\quad$ PH: The $\mathrm{pH}$ value of the in situ clay mask was determined using a digital pH meter. One gram of Mask is dissolved in $100 \mathrm{ml}$ of distilled water and stored for two hours. The $\mathrm{pH}$ measurements of the formula were made in triplicate and the average value was found to be $7.3 .^{8}$

- Spread ability: The spreading capacity of the clay mask was found to be $1.8 \pm 0.3 \mathrm{~cm}$, respectively.

- Skin irritation: The clay mask is formulated to produce no skin irritation or sensitization, when applied to the skin; otherwise it would not be appropriate to be applied to the skin. Therefore, the formulation of the clay mask was investigated for skin irritation using the modified Draize scoring technique. ${ }^{8}$

- Stability test: Stability tests were carried out at different temperatures of $10^{\circ} \mathrm{C}, 20^{\circ} \mathrm{C}, 30^{\circ} \mathrm{C}, 40^{\circ} \mathrm{C}, 50^{\circ} \mathrm{C}, 60^{\circ} \mathrm{C}$. Visual testing was performed at each temperature. The formulation was found to be stable and good up to $43^{\circ} \mathrm{C}$, the formulation was found to be unstable at $53^{\circ} \mathrm{C}$ and $63^{\circ} \mathrm{C}$. The Stability test evalutions were shown in the Table 3.

- $\quad$ Erythema and Edema Scoring Method for Skin Reactions: From the observed results, no edema and no rash were observed on the skin surface and the score was found to be 0 in both cases. ${ }^{9}$

- Patch test: The non-irritating properties of the preparation were assessed by patch testing. This test is done to evaluate the safety of the mask on the application. Although all formulations contain natural ingredients, from a safety point of view, we have performed this test for three parameters; namely, Initial Irritation Test, Delayed Hypersensitivity and Visual Irritation or Allergies and procedures for all tests are as follows: ${ }^{9}$

a) Primary Irritation: In this trial, 24 volunteers were selected. A determined amount of the prepared mask is applied in combination with purified water and honey separately to the back area or the palm of the arm for 30 days. Before applying the mask, any signs of irritation are noted. No obvious reaction or intense erythema or erythema with edema and erosion of vesicles. Seven formulations were evaluated according to the same procedure and possible reactions of varying degrees of non-irritating, + mildly irritating, ++ moderately irritating, +++ high. The Primary irritation index evalutions were shown in the Table 2 .

b) Delayed hypersensitivity: The delayed hypersensitivity test was performed with the same procedure as in the initial irritation test by increasing application and compliance time. After the mask was removed from the skin, responses were measured for $2.5 \mathrm{hr}$ and recorded..$^{10}$

c) Photo irritation/allergy: Some ingredients can produce an allergic reaction only when exposed to light (usually UV light). This test is intended to know the possible photo allergic reactions of the face masks prepared when exposed to the sun on the application. All formulated face masks are applied as in the initial irritation tests and individuals should be exposed to the sun and possible reactions such as itching, allergies, irritation and signs of redness after washing have been measured and recorded. ${ }^{11}$

\section{Ethical Consideration}

Ethical approval and clearance was obtained from the ASPM's K.T. Patil College of Pharmacy, Osmanabad and Maharashtra. The Ethical committee permission letter Registration number is $1347 / \mathrm{ac} / 10$ / CPCSEA.

\section{RESULTS}

The purpose of the clay mask formula has been successful with good results. This mask relieves skin problems. Clay masks (Figure 1) exhibit good spread ability. The formula shows good property on human skin without causing skin irritation or edema. Research also reveals that the formula has the ability to enlarge pores and improve skin cleansing by removing dead skin on the surface. Rashes and blemishes were also seen to remove marks after 20-30 days; by retaining moisture and nutrients inside the skin. This formula has been studied for stability and thermodynamic stability. This formulation gives good stability results and is stable up to $40^{\circ} \mathrm{C}$. The Erythma and skin irritation test were performed 
Table 1: List of ingredients used in preparation.

\begin{tabular}{|c|c|c|c|}
\hline $\begin{array}{l}\text { Sr. } \\
\text { No }\end{array}$ & Name of Ingredients & Uses & $\begin{array}{l}\text { Quantity } \\
\text { (\%) }\end{array}$ \\
\hline 1 & Arjuna Bark & Reduces acne scars (ghadde) & $6 \mathrm{gm}$ \\
\hline 2 & Amba Haldi & $\begin{array}{l}\text { Antibacterial antifungal } \\
\text { gives Glowing skin. }\end{array}$ & $6 \mathrm{gm}$ \\
\hline 3 & Aloe vera & $\begin{array}{l}\text { Antioxidant, moisturizing } \\
\text { agent reduce ance } \mathrm{n} \text { dark } \\
\text { spots,reduce wrinkles } \mathrm{n} \\
\text { signs of agening }\end{array}$ & $5 \mathrm{gm}$ \\
\hline 4 & Rose petal powder & Used as a toner for face & $5 \mathrm{gm}$ \\
\hline 5 & Manjishta & For skin brightening & $5 \mathrm{gm}$ \\
\hline 6 & Methyl Cellulose & Thickener & $\begin{array}{l}0.1 \text { to } \\
1.0 \%\end{array}$ \\
\hline 7 & Distilled water & Vehicle & q.s. \\
\hline 8 & Bentonite & $\begin{array}{l}\text { Suspending and colloidal } \\
\text { agent, adsorbent property }\end{array}$ & 1 to $8 \%$ \\
\hline 9 & Kaolin & $\begin{array}{l}\text { Absorbs sebum and prevents } \\
\text { pore clogging }\end{array}$ & 5 to $40 \%$ \\
\hline 10 & Propylene glycol & Humectant & 2 to $10 \%$ \\
\hline 11 & Sodium lauryl sulfate & Emulsifier or surfactant. & 2 to $20 \%$ \\
\hline 12 & Methyl Paraben & Preservative & q.s \\
\hline
\end{tabular}

Table 2: Evaluation of Primary Skin Irritation Index (PII).

\begin{tabular}{cc}
\hline Irritant Evaluations & Score \\
\hline Non & 0 \\
Slight & $0.1-0.4$ \\
Moderate & $0.41-1.9$ \\
Negligible & $2.0-4.9$ \\
\hline
\end{tabular}

Table 3: Stability testing of the formulation.

\begin{tabular}{cccc}
\hline Sr.No. & Temperature & Physical Appearance & $\mathrm{pH}$ \\
\hline 1 & $10^{\circ} \mathrm{C}$ & Good & 6.5 \\
2 & $20^{\circ} \mathrm{C}$ & Good & 6.5 \\
3 & $30^{\circ} \mathrm{C}$ & Good & 6.5 \\
4 & $40^{\circ} \mathrm{C}$ & Good & 6.5 \\
5 & $50^{\circ} \mathrm{C}$ & More viscous & 6.3 \\
6 & $60^{\circ} \mathrm{C}$ & Solidify & 6 \\
\hline
\end{tabular}

on healthy female volunteers. Research reveals that this formula has the ability to open pores and improve skin cleansing by removing dead skin on the surface and leaving skin clean, clear, luminous and Brighter.

\section{DISCUSSION}

People today require a remedy for a variety of skin disorders that is free of adverse effects. Herbal ingredients made it possible to create cosmetics that had no negative side effects. Herbal face packs are thought to be a long-lasting and effective technique to improve skin's appearance. Thus, the current study is an excellent attempt to make a herbal face pack using naturally occurring substances such as Arjuna Powder, Amba haldi, Aloe Vera, Rose Petal Powder, and Manjishta. The developed formulation was said to be physicochemical and microbiologically stable, and to

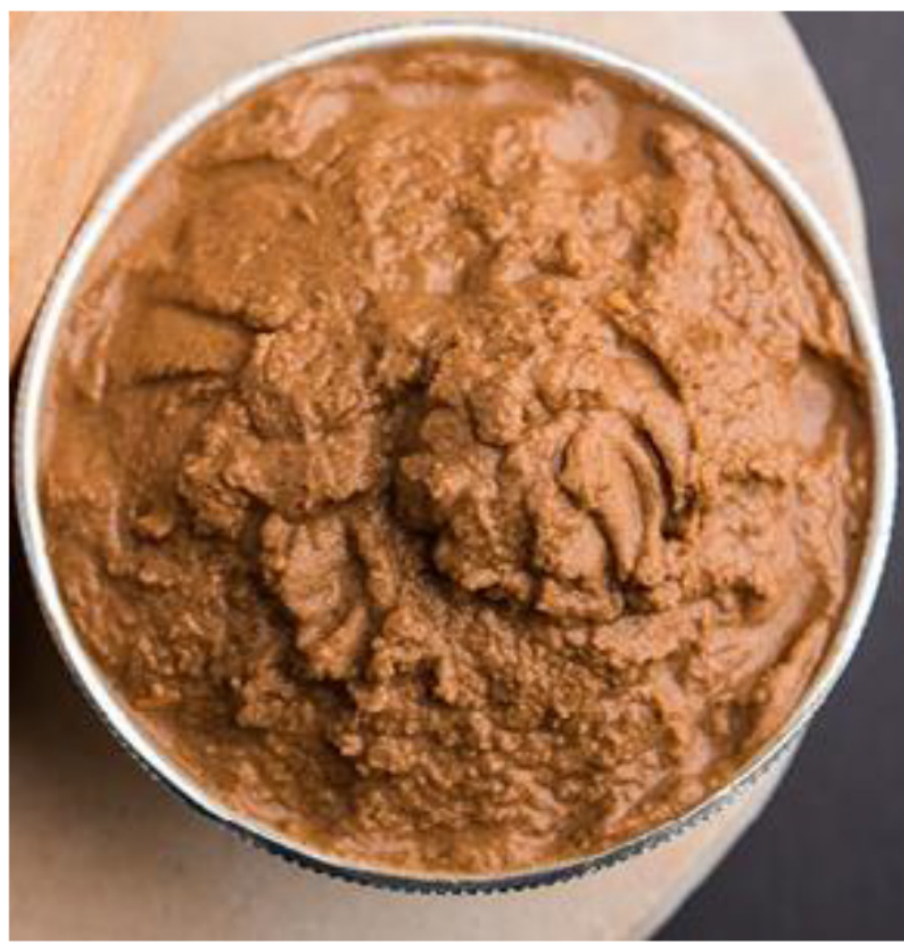

Figure 1: Prepared Face Pack.

have the properties of a typical cosmeceuticals skincare formulation. Herbal face packs or masks are used to improve blood circulation, revitalize muscles, and retain skin elasticity while also removing dirt from pores. Herbal cosmetics have the advantage of being non-toxic, reducing allergic reactions, and many components having a long history of use. The consistency was semisolid and the color was ceramic yellow. The formulation was determined to be homogeneous, washable, and somewhat alkaline in $\mathrm{pH}$, all of which were compatible with normal skin physiology. Formulation properties to achieve soft, fresh, and clean.

Herbal face packs or masks are used to stimulate blood circulation, rejuvenates the muscles and help to maintain the elasticity of the skin and remove dirt from skin pores. The advantage of herbal cosmetics is their non-toxic nature, reduce the allergic reactions and time tested usefulness of many ingredients. Formulation was creamish yellow in colour and had semisolid consistency. The formulation was found homogenous, easily washable and also had very slightly alkaline $\mathrm{pH}$ which were compatible with normal skin physiology. Results of this study show that treatment with clay facial masks can reduce pustules, papules, cysts, and comedones as well as the impact of dermatological conditions on quality of life. However, these study results are limited by design and quality. In conclusion, the present study gives preliminary evidence that healing clay facial masks can be an effective treatment for lesioned skin and mild Acne vulgaris. The oil-absorbing properties of the clays and the cleaning ability of the surfactant system provide the real benefit of the mask.

Clay face packs are by far the perennial favorite. China clay, colloidal kaolin, Fuller's earth, or smectite clay (that is bentonite, magnesium aluminum silicate, and hectorite) may be used as the "argillaceous" material. The naturally occurring smectite clays, commonly referred to as bentonite and kaolin clays aretypically the primary ingredients of a clay face pack. Bentonite gels have been described as soothing to the skin. These facepack have also been used in a number of dermatological preparations such as acne treatment masks with benzoylperoxide. 
These facepack can also play a significant role in the treatment of eczema, abscesses, sores, and wounds. It is suggested that the prepared formulation was physico-chemically and microbiologically stable, and possessed characteristics of a standard cosmeceuticals formulation for skincare. Herbal face packs or masks are used to stimulate blood circulation, rejuvenates the muscles and help to maintain the elasticity of the skin and remove dirt from skin pores. The advantage of herbal cosmetics is their nontoxic nature, reduce the allergic reactions and time tested usefulness of many ingredients. Formulation was creamish brown in colour and had semisolid consistency. The formulation was found homogenous, easily washable and also had very slightly alkaline $\mathrm{pH}$ which were compatible with normal skin physiology. Consequently, it exhibited good flow properties for formulation to achieve soft, fresh and clean formulation. after Freeze-Thaw, it was found that creamy texture was slightly rough, very viscous, light brown color, smell the clay, and there was no layer separation of pack. It can be seen that this herbal facial mask cream was well stability.

\section{CONCLUSION}

Natural medicines are more acceptable since they are believed to be safer and have less adverse effects than synthetic therapies. Natural therapies are more accepted because they are believed to have fewer adverse effects than manufactured ones. Herbal face packs are used to promote blood circulation, which helps to renew muscles and retain skin elasticity while also removing debris from pores. Herbal cosmetics have the advantage of being nontoxic, reducing allergic reactions, and many substances having a long history of use.

\section{ACKNOWLEDGEMENT}

The authors are thankful to College of Pharmacy ASPM's K.T Patil College of Pharmacy, Osmanabad for providing sample, providing necessary facilities and to carry out this work and microbiological study. I am also thankful to Dr. Amol A. Joshi, Principal K. T. Patil College of Pharmacy who gives me endless support for my research work.

\section{CONFLICT OF INTEREST}

The authors declare that there is no conflict of interest.

\section{REFERENCES}

1. Okereke JN, Udebuani AC, Ezeji EU, Obasi KO, Nnoli MC. Possible health implications associated with cosmetics: A review, Sci. J Public Health. 2015;5(1):58-63.

2. Lupo MP. Antioxidants and Vitamin $S$ in cosmetics. Clin Dermatol. 2001;19(4):467-73. doi: 10.1016/s0738-081x(01)00188-2, PMID 11535390.

3. Available from: http://epgp.inflibnet.ac.in/epgpdata/uploads/epgp_content/ S000833PL/P001869/M031293/ET/1527678259P11M31Text.pdf [cited 24/11/2021]

4. SS, DSK, PA. Wound Healing Potential of Aloe vera Leaf Gel Studied in Experimental Rabbits. Asian J Biochem. 2006;1(2):178-85. doi: 10.3923/ ajb.2006.178.185.

5. Ram A, Lauria P, Gupta R, Kumar P, Sharma VN. Hypocholesterolaemic effects of Terminalia arjuna tree bark. J Ethnopharmacol. 1997;55(3):165-9. doi: 10.1016/ s0378-8741(96)01493-6, PMID 9080336

6. Mate A, Ade P, Pise A, More S, Pise S, Kharwade R. Formulation and evaluation of polyherbal gel for the management of acne. Int J Curr Res Rev. 2021;13(4):117-22. doi: 10.31782/IJCRR.2021.13432.

7. Ingle A, Mayuri B. Meshram Formulation and evaluation of ayurvedic face wash. Int J Phytopharmacol. 2018;8(3):26-30.

8. Millikan LE. Cosmetology, cosmetics, cosmeceuticals: Definitions and regulations. Clin Dermatol. 2001;19(4):371-74. doi: 10.1016/s0738081x(01)00195-x, PMID 11535376.

9. Ashawat MS, Banchhor M. Herbal Cosmetics Trends in skin care formulation. Pharmacogn Rev. 2009;3(5):82-9.

10. Kanlayavattanakul $M$, Lourith $N$. Therapeutic agents and herbs in topical application for acne treatment. Int J Cosmet Sci. 2011;33(4):289-97. doi: 10.1111/j.1468-2494.2011.00647.x, PMID 21401650.

11. Chanchal D, Swarnlata S. Herbal Photoprotective Formulations and their Evaluation. Open Nat Prod J. 2009;2(1):71-6. doi: 10.2174/1874848100902010071.

12. Indian standard, face pack-specification, IS 15153 [cited Aug 05 2016]; 2002, August 2002.

13. Rani SR. Text book of Industrial pharmacy, Drug delivery systems and Cosmetics and Herbal drug technology. 2nd ed. India: Universities press Ltd; 2002.

14. Hwang JK, Shim JS, Gwon SH, Kwon YY, Oh HI, et al Novel use of Panduration derivatives or extract of Kaempferia panduratacomprising the same. U.S Patent 0065272A1; 2012 [cited Aug 05 2016].

15. Buhse L, Kolinski R, Westenberger B, Wokovich A, Spencer J, Chen CW, et al. Topical drug classification. Int J Pharm. 2005;295(1-2):101-12. doi: 10.1016/j. ijpharm.2005.01.032, PMID 15847995.

16. Banchhor M, Ashawat MS, Saraf S, Saraf S. Herbal cosmetics: Trends in skin care formulation. Pharmacogn Rev. 2009;3(5):82-9.

17. Mandeep S, Shalini S, Sukhbir LK, Ram KS, Rajendra J. Preparation and evaluation of herbal cosmetic cream. Pharmacologyonline. 2011:1258-64.

18. Umar S, Akhila A, Naqvi AA, Farooqi AH, Singh AK, Singh D, et al. Medicinal plants in skin care. Lucknow, India: Central Institute of Medicinal and Aromatic Plants; 1994;1:1-10. 